\title{
Material and Manufacturing Properties of Bracket Mural Paintings of Daeungjeon Hall in Gaeamsa Temple, Buan
}

\author{
Hwa Soo Lee', Yeong Gyeong Yu², Kyeong-Soon Han ${ }^{1, *}$ \\ ${ }^{1}$ Department of Formative Arts, Konkuk University, Chungju 27278, Korea \\ ${ }^{2}$ Department of Fine Arts, General Graduate School, Konkuk University, Chungju 27278, Korea
}

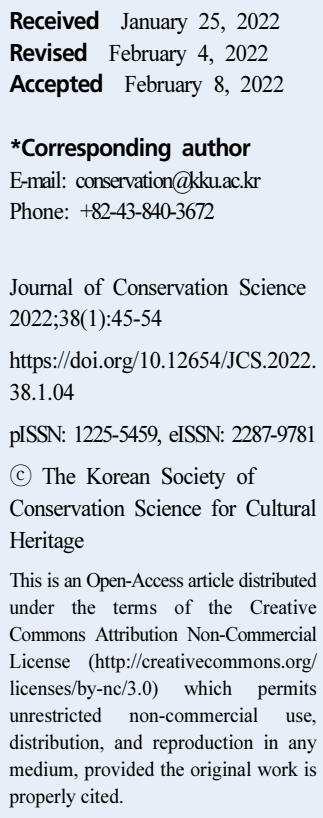

\begin{abstract}
This study examined the production technique of bracket murals in Daeungjeon Hall, Gaeamsa Temple by conducting a analysis of their wall structure, material characteristics, and painting layers. Wall was a single-branch structure with support layer, middle layer, finishing layer, and painting layer. The support layer, middle layer and finishing layer, were produced by mixing sand (quartz, feldspars etc.), and loess. The ratio of above medium sand to below fine sand was approximately $0.7: 9.3$ in the support layer, $4: 6$ in the middle layer and $6: 4$ in the finishing layer, which had a more percentage of above medium sand than the support layer. The analysis of the painting layer showed that natural soil pigment was used to establish a relatively ground layer of up to $50 \mu \mathrm{m}$, and pigments such as Lead sulfate, atacamite and mercury sulfide were painted on top of the layer. This study's results confirmed that the bracket mural paintings in Gaeamsa Temple are within the category of the production style of murals during the Joseon period. However, the points that the middle layer was formed several times, the significant difference in particle size distribution between the wall, and the absence of chopped straw in the support layer are a feature of bracket mural paintings in Gaeamsa Temple. These properties of murals as material and structure may be viewed for correlation with the degree of damage to wall structure of mural painting and would serve as an important reference to diagnosis the conservation conditions of murals or prepare conservation treatments.
\end{abstract}

Key Words Buddhist mural paintings, Earthen wall, Manufacturing technique, Material properties, Conservation

\section{INTRODUCTION}

Temple murals in Korea were painted on the mud wall of wooden buildings, and natural pigments and the vehicle were mixed to produce the painting layer after the wall was built with tree branches as its frames on top of wooden furniture and the soil as its major material (Lee, 2013). Murals, whose materials are mostly soft in nature, are reported to be vulnerable for conservation due to their material characteristics and the environmental factors in their locations (Lee et al., 2018a). Furthermore, due to some treatments conducted on temple murals in early days of the conservation of temple murals in Korea when there was a lack of studies on mural materials and manufacturing techniques, many murals have been damaged or made difficult for coneservation, which calls for a study on the manufacturing characteristics of murals. Hence, if materials and techniques used in the production of murals are identified accurately, it would make it possible to conduct a reliable study on the conservation of murals and suggest more systematic and effective conservation options (Lee, 2013).

Studies on the material characteristics and manufacturing techniques of temple murals in Korea include the first study in 2006 that scientifically demonstrated the traditional materials and manufacturing techniques of four-sided interior murals in Geungnakjeon Hall, Muwisa Temple, Gangjin (Chae et al., 2006; Fine Art Conservation Institute, 2006) and a 2008 study conducted on manufacturing techniques based 
on the material characteristics of Yeongsan Hoesang murals in Bongjeongsa Temple, Andong (Jeong and Han, 2008). Since then, there were studies comparing the characteristics of manufacturing techniques in temple murals, including murals at the back of the altar in Daeungjeon Hall, Heungguksa Temple, Yeosu, exterior murals in Mireukjeon Hall, Geumsansa Temple, Gimje, and murals at the back of the altar in Daeungjeon Hall, Seonunsa Temple, Gochang (Lee, 2016; Han, 2010). In particular, while studies in the past focused on scientific investigations about relatively important temple murals, studies are being conducted around 2020 by closely interpreting mural materials and production techniques and proposing conservation measures about bracket murals in Daeungjeon Hall, Jikjisa Temple (Lee et al., 2018a) and bracket murals in Daeungbojeon Hall, Naesosa Temple (Lee et al., 2018b).

Daeungjeon Hall, Gaeamsa Temple, Buan is currently designated as Treasure No. 292 and has 52 murals, including bracket murals painted on interior and exterior walls and murals at the top of Nemok-dori (Figure 1). While there are 32 interior bracket murals with 6 each on the east and west and 10 each on the south and north, 4 on the north have no painted image and 5 have been repainted relatively lately. The latest scientific investigation on bracket murals in Daeungjeon Hall, Gaeamsa Temple found that damage in the wall and damage due to the deteriorated painting layer had gotten worsen, which would require conservation treatment (Figure 2). Accordingly, a study identifying manufacturing conditions based on structures and materials, which constitute murals, would need to be conducted first to prepare stable

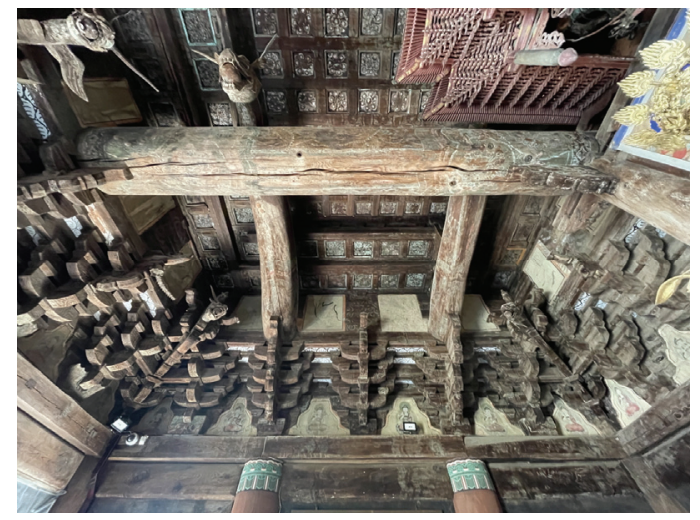

Figure 1. Inside the Daeungjeon hall of Gaeamsa Temple, Buan. conservation options.

In this context, this study identified the manufacturing characteristics of bracket murals in Daeungjeon Hall, Gaeamsa Temple by closely analyzing the wall and painting layer consisting of the murals and wish to offer an effective reference for diagnosis the conservation conditions and prepareing conservative treatment of murals in the future.

\section{METHOD}

\subsection{Structure of mural painting}

The structure of the mural painting was investigated by visually observing the damaged or broken wall of the mural and observing the cross-section with a microscope. Murals are basically divided into the wall and the painting layer, and categorized further into additional layers depending on their making process. To begin with, the structure of layers around damaged parts of the wall was investigated and the thickness of each layer was measured. For the painting layer, the cross-section of murals whose pigments were retrieved was examined to identify the painting layer thickness by color.

\subsection{Analysis of material properties}

With the structure of the murals, this study conducted a physical and chemical analysis on materials consisting of the wall and the painting layer to identify the characteristics of the materials. Samples which came off of the murals were used for analysis, and the following analyte and analytical

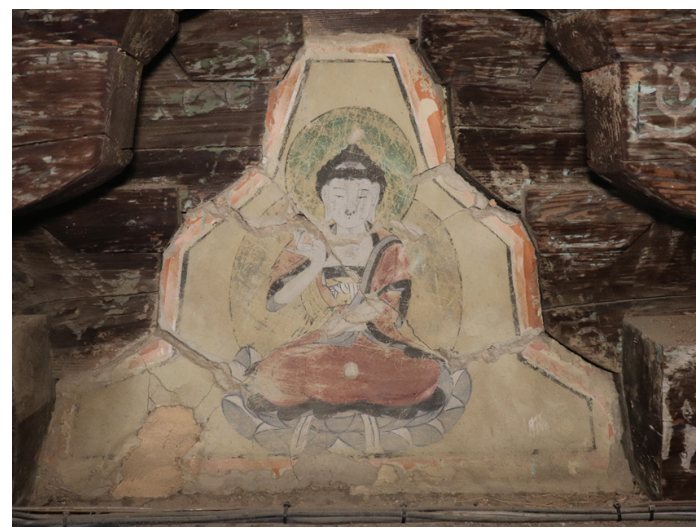

Figure 2. Example of conservation status of murals in Gaeamsa Temple, Buan. 
Table 1. List of analysis objects

\begin{tabular}{|c|c|c|c|}
\hline Sample name & \multicolumn{2}{|c|}{ Description } & Location \\
\hline S1 & \multicolumn{2}{|c|}{ Support layer } & South side $1^{\text {st }}$ mural \\
\hline M1 & \multicolumn{2}{|c|}{ Middle layer } & North side $3^{\text {rd }}$ mural \\
\hline F1 & \multicolumn{2}{|c|}{ Finishing layer } & East side $3^{\text {rd }}$ mural \\
\hline G1 & \multicolumn{2}{|c|}{ Ground layer } & South side $4^{\text {th }}$ mural \\
\hline P1 & \multirow{4}{*}{ Painting layer } & White color & West side $1^{\text {st }}$ mural \\
\hline $\mathrm{P} 2$ & & Green color & West side $1^{\text {st }}$ mural \\
\hline P3 & & Red color & West side $2^{\text {nd }}$ mural \\
\hline $\mathrm{P} 4$ & & Green color & West side $2^{\text {nd }}$ mural \\
\hline
\end{tabular}

Table 2. List of analysis object and analysis equipment for mural painting

\begin{tabular}{|c|c|c|c|}
\hline Sample name & Classification & Ana & ysis equipment \\
\hline \multirow{6}{*}{$\mathrm{S} 1, \mathrm{M} 1, \mathrm{~F} 1$} & Investigation of naked eye & Digital camera & G15, Canon, Japan \\
\hline & Microscopic analysis & Stereoscopic microscope & SMZ18, Nikon, Japan \\
\hline & Microstructure chemical component & SEM-EDS & JSM-7610F, JEOL, Japan \\
\hline & Crystal phase & XRD & Miniplex 600, Rigaku, Japan \\
\hline & Particle size & PSA & Testing sieve, JIS Z 8801, Japan \\
\hline & Wood and fiber identification & Digital microscope & G-scope, Genie Tech, Korea \\
\hline \multirow{3}{*}{$\begin{array}{l}\text { G1, P1, P2 } \\
\text { P3, P4 }\end{array}$} & Investigation of naked eye & Digital camera & G15, Canon, Japan \\
\hline & Microscopic analysis & Digital microscope & G-scope, Genie Tech, Korea \\
\hline & $\begin{array}{l}\text { Microstructure chemical component } \\
\text { elemental mapping }\end{array}$ & SEM-EDS & JSM-7610F, JEOL, Japan \\
\hline
\end{tabular}

method were used (Tables 1 and 2): For the analysis of material characteristics, a basic investigation was conducted first with the stereo microscope (SMZ18, Nikon, JPN) and the digital microscope (G-scope, Genie Tech, KOR) and then microstructure and chemical composition analyses were conducted with the scanning electron microscope and the energy dispersive X-ray fluorescence spectrometer (JSM-7610F, JEOL, JPN). Furthermore, to analyze the characteristics of materials in the wall, the X-ray diffractometer (Miniplex 600, Rigaku, JPN) was used to identify the mineral crystal habit, while a wet sieve analysis based on the standard stainless sieves (JIS Z 8801, Okutani Ltd., JPN) was conducted to identify the distribution ratio of particle sizes in the wall. For the classification of particle sizes, their residual weight was measured in accordance with standards from the United States Department of Agriculture (USDA) and the International Union of Soil Sciences (IUSS) and represented in cumulative percentages.

\section{RESULTS}

\subsection{Properties of wall layer}

\subsubsection{Structure of wall}

The walls of the bracket murals in Gaeamsa Temple were made with soil around the branches were tied with straw rope. On the top of the branches that serve as the frame of the wall, a support layer in the form of plastering a mixture of fine loess and sand is confirmed, and a layer of sand with large particles and various sizes is observed above it, and the corresponding layer has two layers. Separated from above. Bracket murals in Daeungjeon Hall, Gaeamsa Temple, Buan consisted of three layers: the support layer, middle layer, and finishing layer (Figure 3A). In some parts, traces confirmed that the middle layer was made more than once (Figure $3 \mathrm{~B}$ ). 

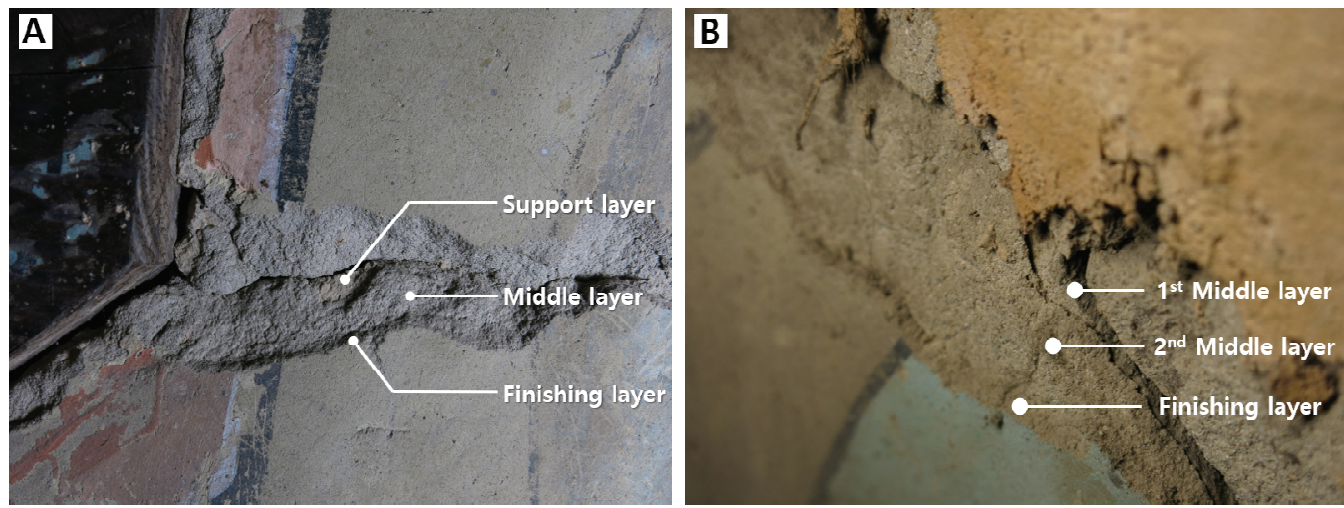

Figure 3. Types of wall layers (A: 3 Layers, 'support layer - middle layer - finishing layer', B: 4 Layers, 'support layer $-1^{\text {st }}$ middle layer - $2^{\text {nd }}$ middle layer - finishing layer').

It is found that the support layer has a thickness of about $50 \mathrm{~mm}$ from the branch, and traces of roughly and quickly plastering appear through the area where the mural has been exfoliated, and a mixed of wooden material and leaves is observed on some walls. The middle layer and finishing layer were applied relatively evenly with a high level of smoothness, the thickness of the middle layer was estimated to be about $7 \mathrm{~mm}$, and the finishing layer to be $3 \mathrm{~mm}$.

\subsubsection{Material of Wall}

Results of microscopic observation of wall samples of the braket mural painting of Daeungjeon Hall in Gaeamsa Temple (Figure 4), while samples from the support layer consisted of below silt particles rather than larger ones like gravel, samples from the middle layer and the finishing layer had a mixture of larger particles like sand grains and silt or like clay. In addition, fibers presumed to have been mixed during the wall manufacturing process were confirmed in all
A

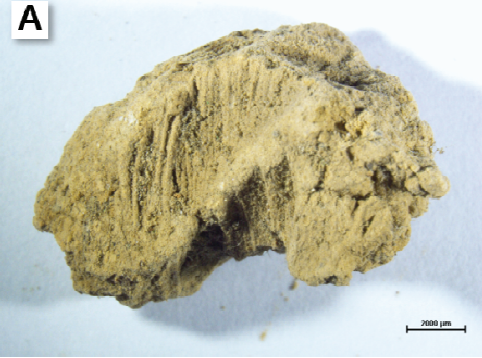

B

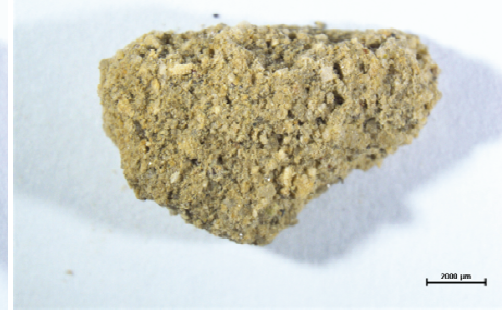

C

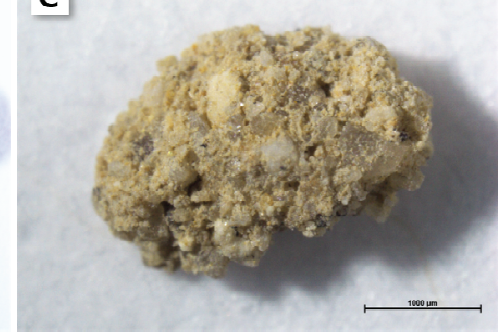

Figure 4. Microscopic image of samples (A: Support layer, B: Middle layer, C: Finishing layer).
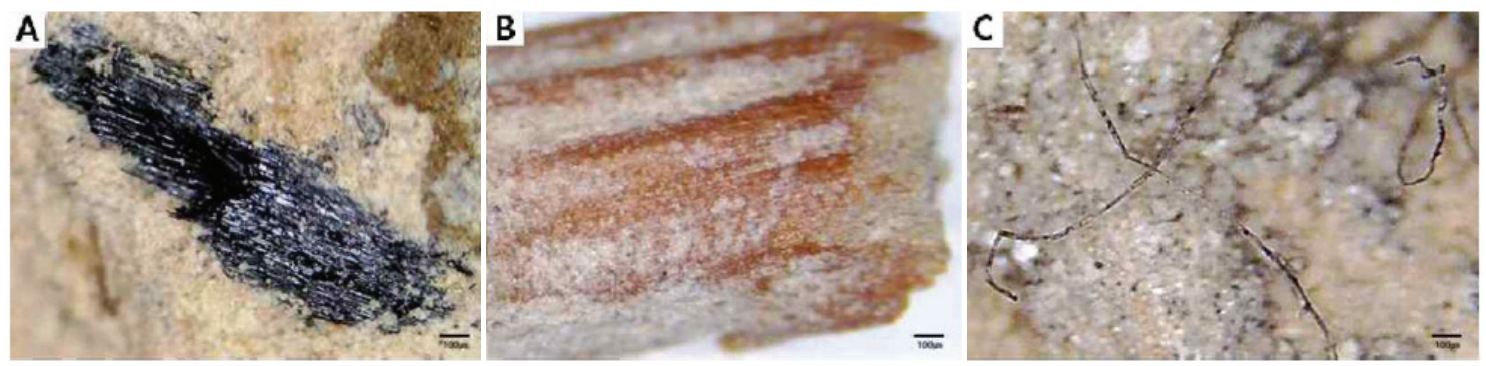

Figure 5. Digital microscope image of wood and fiber mixed in the wall (A: Wood piece in support layer, B: Wood piece in middle layer, C: Fiber in finishing layer). 
samples of the support layer, the middle layer, and the finishing layer.

In the case of the support layer, fibers presumed to be wood or bark were mixed in the wall (Figure 5), and it was confirmed that the fibers of fine thickness were evenly mixed in the middle layer and the finishing layer. The microstructure analysis by the scanning electron microscope confirmed that soil particles such as sand and clay minerals formed aggregates in the support layer, and multiple materials suspected to be fibers were observed. Large and small soil particles were found to have a plate-like microstructure, which was believed to be an aggregate of clay minerals.

In the middle layer and the finishing layer, aggregates of soil particles resembling silt or clay minerals as large and small ones or in the form of plates were observed on the surface of large particles suspected to be quartz. The chemical composition analysis detected silicon (Si), aluminum oxide $(\mathrm{Al})$, iron $(\mathrm{Fe})$, potassium $(\mathrm{K})$, magnesium $(\mathrm{Mg})$, and sodium (Na) in the support layer, and in the middle layer and the finishing layer, atoms usually found in the soil such as iron $(\mathrm{Fe})$, potassium $(\mathrm{K})$, magnesium $(\mathrm{Mg})$, and sodium $(\mathrm{Na})$ were detected, including silicon $(\mathrm{Si})$ and aluminum oxide $(\mathrm{Al})$ like the support layer (Figure 6).

The analysis of the mineral crystal habit detected the mica group, such as muscovite and albite, and feldspars along with quartz in the support layer. In the middle layer, feldspars such as quartz, microcline, and albite were identified, while the same minerals from the initial layer such as quartz, muscovite, and albite were found in the finishing layer. It is estimated that feldspars including quartz and minerals in the mica group were used in bracket murals (Figure 7).

The particle size analysis by the wet sieve (Table 3, Figure 8) found that in terms of distribution in the size of mineral particles used in the support layer of bracket murals, very coarse sand accounted for $3.79 \%$, coarse sand $1.33 \%$, medium sand $1.52 \%$, fine sand $9.47 \%$, very fine sand $15.15 \%$, and below silt $68.75 \%$. For the support layer of bracket murals in Gaeamsa Temple, below fine sand accounted for more than $93 \%$, which led this author to believe that it was mixed with the soil of very fine particles. In terms of distribution in the size of mineral particles used in the middle layer, very coarse sand accounted for $3.40 \%$, coarse sand $23.63 \%$, medium sand $12.70 \%$, fine sand $26.59 \%$, very fine sand $13.59 \%$, and below silt $20.09 \%$. Below fine sand accounted for more than a half of the middle layer, and it had a higher percentage of sand than the support layer. Finally, in terms of distribution in the size of mineral particles used in the finishing layer, very coarse sand accounted for $13.33 \%$, coarse sand $33.33 \%$, medium sand $14.29 \%$, fine sand $19.05 \%$, very fine sand $8.57 \%$, and below
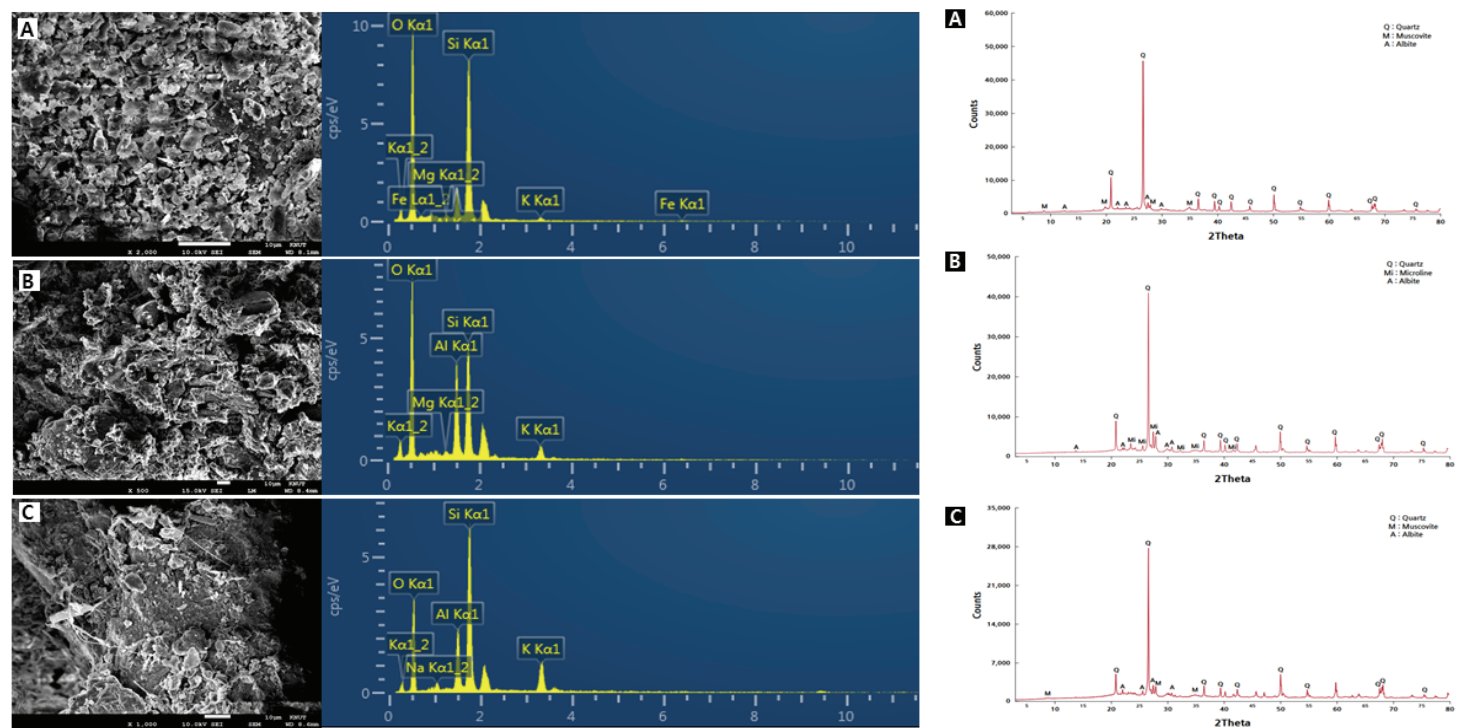

Figure 6. Results of SEM-EDS (A: Support layer, B: Middle layer, C: Figure 7. Results of XRD (A: Support layer, Finishing layer). B: Middle layer, C: Finishing layer). 
Table 3. Results of particle size analysis (unit: \%)

\begin{tabular}{ccccccccccc}
\hline & \multicolumn{2}{c}{ Very coarse sand } & Coarse sand & $\begin{array}{c}\text { Medium } \\
\text { sand }\end{array}$ & Fine sand & Very fine sand & Below silt \\
\cline { 2 - 10 } & Over $1.0 \mathrm{~mm}$ & $1.0-0.5 \mathrm{~mm}$ & $500-300 \mu \mathrm{m}$ & $300-212 \mu \mathrm{m}$ & $212-100 \mu \mathrm{m}$ & $100-75 \mu \mathrm{m}$ & $75-45 \mu \mathrm{m}$ & $45-25$ & $\mu \mathrm{m}$ & below $25 \mu \mathrm{m}$ \\
\hline $\mathrm{S} 1$ & 0.95 & 2.84 & 1.33 & 1.52 & 9.47 & 5.68 & 9.47 & 15.15 & 53.60 \\
\hline $\mathrm{M} 1$ & 0.44 & 2.95 & 23.63 & 12.70 & 26.59 & 5.47 & 8.12 & 10.78 & 9.31 \\
\hline $\mathrm{F} 1$ & 0.48 & 12.86 & 33.33 & 14.29 & 19.05 & 3.81 & 4.76 & 9.52 & 2.38 \\
\hline
\end{tabular}

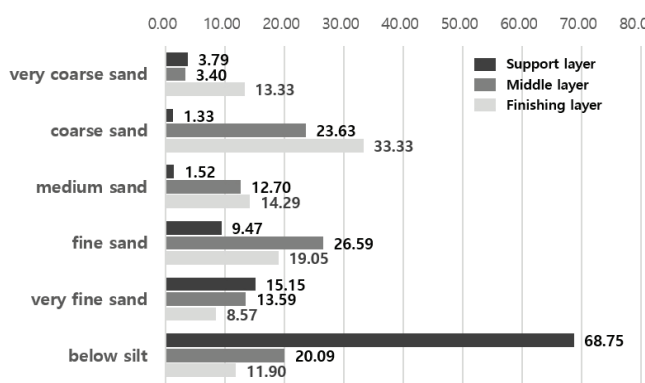

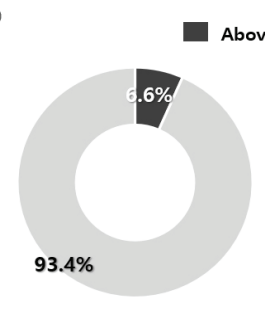

Support layer

Above Medium Sand Below Fine Sand

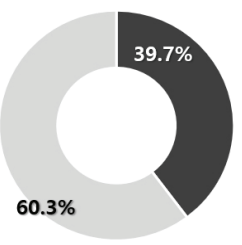

Middle layer

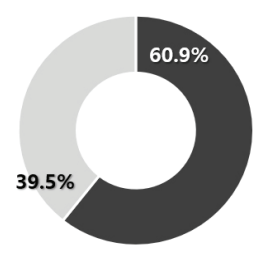

Finishing layer

Figure 8. Results of particle size analysis.

silt $11.90 \%$. Above medium sand accounted for more than a half of the finishing layer of bracket murals, and it had a higher percentage of sand than other layers. When the particle size distribution was divided into above medium sand and below fine sand, the finishing layer had an opposite trend to the middle layer in terms of the particle size distribution.

\subsection{Properties of painting layer}

\subsubsection{Structure of painting layer}

Murals in Daeungjeon Hall, Gaeamsa Temple, Buan were painted in seven colors: white, black, grey, dark green, pale green, red, and flesh color. By examining the surface of the murals, this study identified the ground layer (Figure 9). The retrieved samples were used to investigate the cross-section and showed some traces, confirming that the ground layer was made and painted on top of the finishing layer (Figure 10). The ground layer was pale ochre (off white) and had the thickness of 35 to $50 \mu \mathrm{m}$. The painting layer painted on the ground layer had the thickness of 22 to $80 \mu \mathrm{m}$. The painting layer in the white sample (P1) had thickness with $21.53 \mu \mathrm{m}$ in thin parts and $38.3 \mu \mathrm{m}$ in thick parts, while the painting layer in the green sample (P2) ranged from 45.77 $\mu \mathrm{m}$ to $79.38 \mu \mathrm{m}$ in thickness. In addition, another green sample of P3 other than P2 ranged from $36.33 \mu \mathrm{m}$ to 48.46 $\mu \mathrm{m}$ in thickness, which showed a difference of $2.69 \mu \mathrm{m}$ to $43.05 \mu \mathrm{m}$ from P3, albeit in the same color category. Lastly,

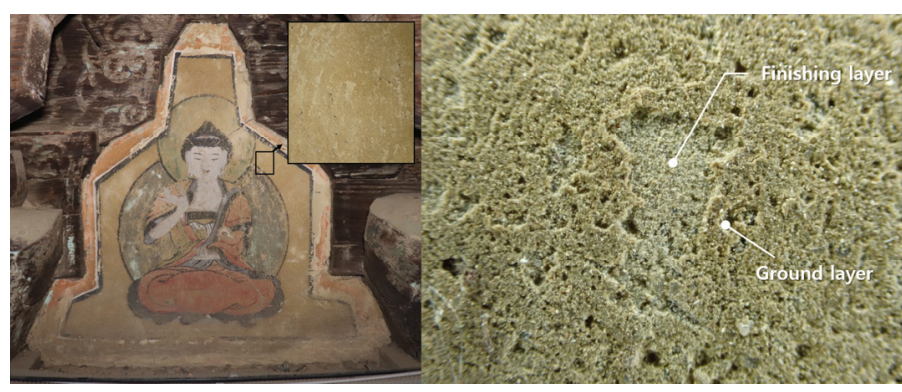

Figure 9. Coloring condition of mural painting.

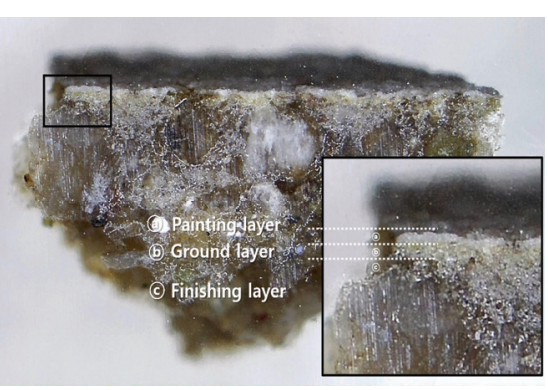

Figure 10. Structure of painting layer. 

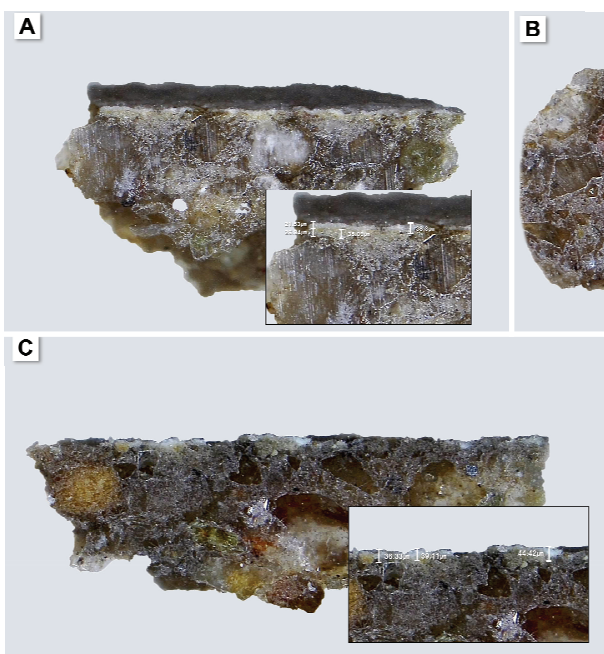

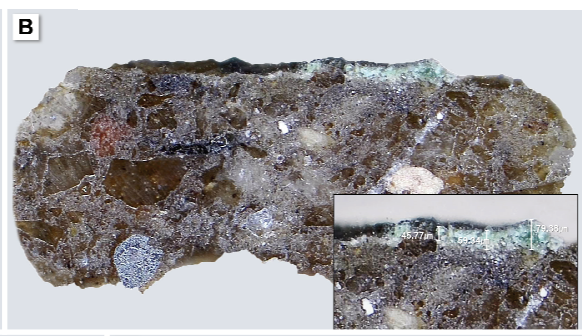

D

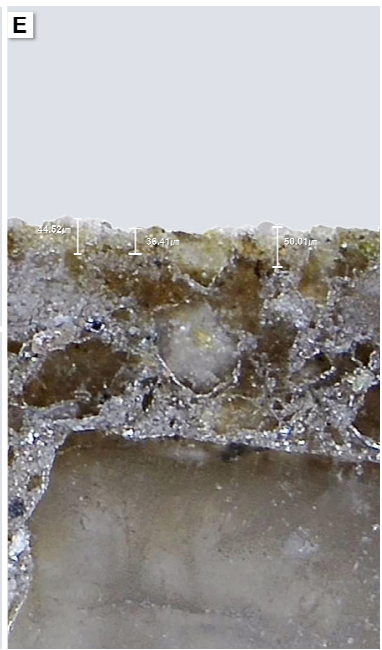

Figure 11. Thickness measurement results for painting layer through cross-section (A: Cross section of P1, B: Cross section of P2, C: Cross section of P4, D: Cross section of P3, E: Cross section of G1).

the red sample (P4) from $26.91 \mu \mathrm{m}$ to $48.46 \mu \mathrm{m}$ in thickness (Figure 11).

\subsubsection{Material of painting layer}

Based on the results of the cross-section investigation into the structure of painting layer, the results of chemical components analyzed from 4 samples from the ground layer and the painting layer are provided in Table 4 and Figure 12. G1 found in the ground layer mainly consisted of silicon (Si) and aluminum oxide (Al), along with calcium (Ca) and iron $(\mathrm{Fe})$. To confirm whether there was the ground layer below the painting layer, samples from the painting layer were analyzed for parts suspected to be the ground layer through the microstructure, which showed the layer below the painting layer in P1 to P4 had the same chemical composition as $\mathrm{G} 1$. The white $\mathrm{P} 1$ was confirmed to contain lead $(\mathrm{Pb})$ and sulfur (S), and the green mainly consisted of $\mathrm{P} 2$ copper $(\mathrm{Cu})$ and chlorine $(\mathrm{Cl})$, along with tin $(\mathrm{Sn})$, lead $(\mathrm{Pb})$, and sulfur (S). P3 had copper $(\mathrm{Cu})$, tin $(\mathrm{Sn})$, lead $(\mathrm{Pb})$, and sulfur (S).
The red P4 mainly consisted of mercury (Hg) and sulfur (S).

\section{DISCUSSION AND CONCLUSION}

By conducting a scientific analysis on the structure and material of the bracket mural paintings inside the Daeungjeon Hall in Gaeamsa Temple, Buan, the characteristics of the walls and painting layer and the method of manufacturing the murals could be grasped. The study results are summarized as follows.

First, an investigation into the wall structure revealed that branches were tied with straw rope and mud plaster was applied three times to produce the earthen wall.

According to studies on the wall structure of buddhist mural paintings in the Joseon Dynasty, showed that the structure of buddhist murals produced across the Joseon period includes distinguished wall into the support layer, middle layer, and finishing layer. Also, most of the support layer and middle layer generally have chopped straw mixed.

Table 4. Results of SEM-EDS

\begin{tabular}{|c|c|c|c|}
\hline Sample name & & & Major elements \\
\hline G1 & & & $\mathrm{Al}, \mathrm{Si}, \mathrm{Ca}, \mathrm{Fe}$ \\
\hline $\mathrm{P} 1$ & \multirow{4}{*}{ Painting layer } & White color & $\mathrm{Pb}, \mathrm{S}$ \\
\hline $\mathrm{P} 2$ & & \multirow{2}{*}{ Green color } & $\mathrm{Cu}, \mathrm{Cl}, \mathrm{Sn}, \mathrm{Pb}, \mathrm{S}$ \\
\hline $\mathrm{P} 3$ & & & $\mathrm{Cu}, \mathrm{Sn}, \mathrm{Pb}, \mathrm{S}$ \\
\hline P4 & & Red color & $\mathrm{Hg}, \mathrm{S}$ \\
\hline
\end{tabular}



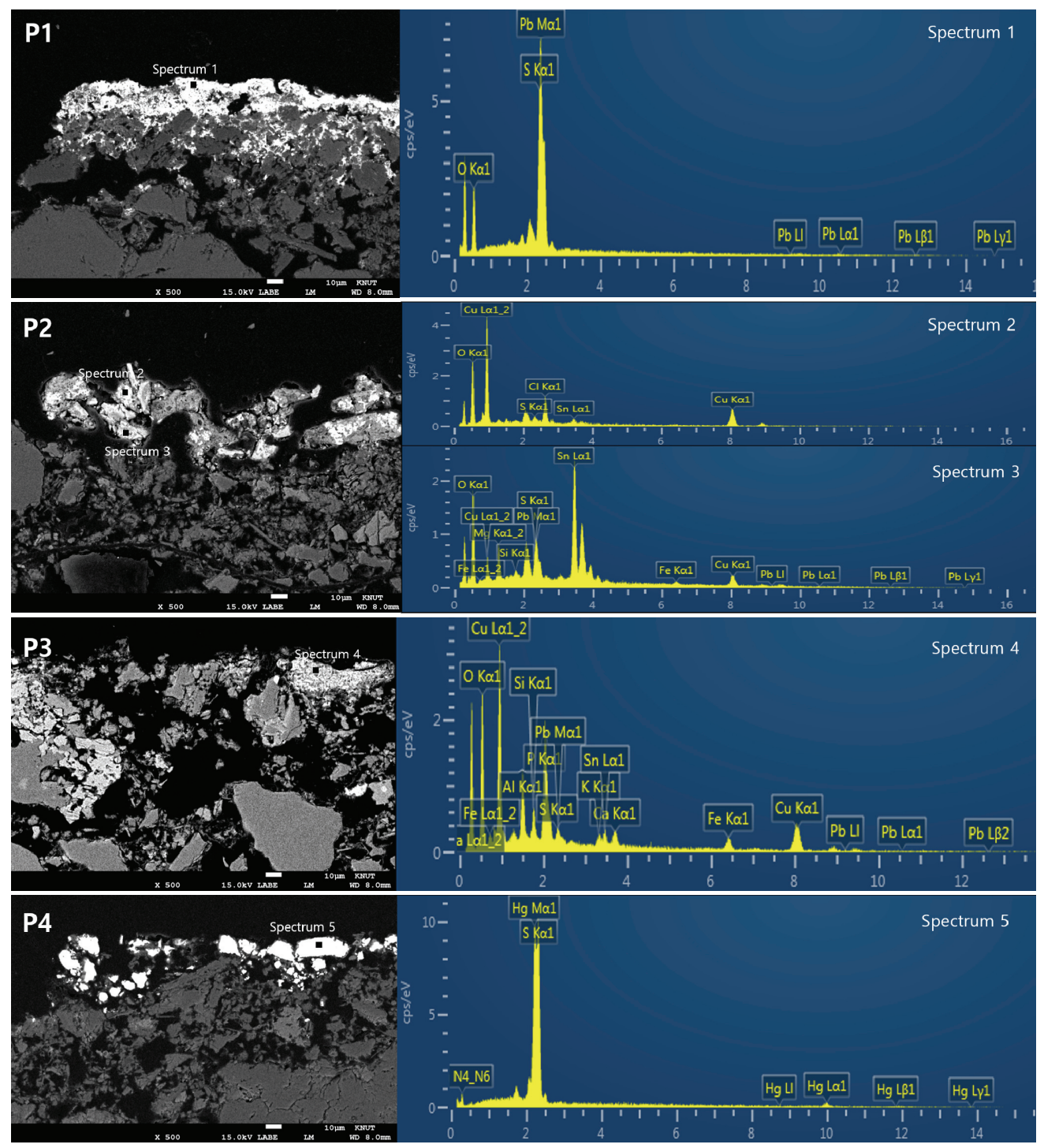

Figure 12. Results of SEM-EDS.

Like some murals at Naesosa Temple in Buan, these types in which the absence of the middle layer and wooden materials mixed, but this does not belong to the general manufacturing style of buddhist mural paintings (Lee et al., 2018b).

Comparing the characteristics of the previously reported buddhist murals with the bracket murals of Daeungjeon Hall in Gaeamsa Temple, it can be that the murals at Daeungjeon at Gaeamsa belong to the category of general buddhist mural paintings. However, it is not a general tendency that the middle layer is applied more than once, that wood is mixed in the wall, and that materials presumed to be chopped straw were rarely identified. The thickness of the bracket murals of Daeungjeon Hall in Gaeamsa Temple was investigated to be about $60 \mathrm{~mm}$, and the thickness of the support layer was about $50 \mathrm{~mm}$. This result is similar to the thickness of the general buddhist murals, but compared to the murals in which the middle and finishing layers are created one at a time with a thickness of about $10 \mathrm{~mm}$, the bracket murals of Daeungjeon Hall in Gaeamsa Temple have two or more layers. It seems that the middle layer and finishing layers of Gaeamsa Temple's mural paintings have a thin thickness. Multiple applications of thin walls have the advantage of preventing cracks and allowing the walls to dry well (Hwang, 
2008). While if it is manufactured without considering the particle size, the adhesive force between the layers may be lowered, thereby aggravating the damage caused by the separation between the layers. And since fiber reinforcements used in the wall, such as chopped straw, prevent cracks and dispersions due to the contraction of the wall (Han, 2003), the absence of such materials would serve as a vulnerability if physical damage to the wall occurs.

An analysis of the microstructure and chemical composition of particles consisting of each layer of bracket murals detected soil particles of various sizes or crystal aggregates in plates and chemical components usually found from soil materials such as silicon $(\mathrm{Si})$ and aluminum oxide (Al). Furthermore, the mineral crystal habit such as quartz and feldspars was identified, demonstrating that the main materials of the wall layer and the finish layer were weathered soil and sand originating from rocks, which is consistent with the results of a previous study on the wall material characteristics of temple murals (Lee, 2016).

A particle size analysis found that the support layer had a high content of loess, while the middle layer and the finishing layer had a fairly high content of sand. In the support layer, above medium sand accounted for $7 \%$ and below fine sand $93 \%$. And since the proportion of soil less than silt is $53.6 \%$ even in the soil of fine sand or less, it is estimated that the support layer is made by mixing soil of relatively even and fine soil materials to produce the murals. In the middle layer, above medium sand accounted for $40 \%$ and below fine sand $60 \%$, showing that it had a higher fine sand content than the support layer. In the finishing layer, above medium sand accounted for $60 \%$ and below fine sand $40 \%$, compared to other layers, the proportion of very coarse sand and coarse sand size soil is high, indicating that the content of large sand is high. The difference in the particle size distribution of the soil at each layer indicates the difference in the voids according to the arrangement of the soil particles, and the attractive force according to the particle gap affects the cracks or strength of the wall, which is directly related to the conservation of the mural. In particular if moisture were absorbed and released repeatedly in the wall, this condition would lead to changes in the volume fraction between wall layers, create a difference in stress over the long term, and cause physical damage such as cracks and separations between the layers
(Lee et al., 2018b). As it can be seen that the pattern of damage confirmed in the current murals of Gaeamsa Temple reflects some of these structural and material characteristics, attention is required for the conservation of the murals.

An analysis of samples by the digital microscope found five colors: white, dark green, pale green, red as well as ochre in the ground layer. From the ochre ground layer, silicon (Si), aluminum oxide $(\mathrm{Al})$, calcium $(\mathrm{Ca})$, and iron $(\mathrm{Fe})$ were detected as the main components, which suggest soil pigments such as loess or kaolinite may have been used. In the white color layer, lead $(\mathrm{Pb})$ and sulfur $(\mathrm{S})$ were the main components, and lead (II) sulfate seems to be have been used. For green, copper $(\mathrm{Cu})$ and chlorine $(\mathrm{Cl})$ were observed as the main components, and atacamite may have been used. For red, mercury (Hg) and sulfur (S) were detected, showing that mercury sulfide pigments may have been used. The existence of the ground layer and the pigments used in the painting layers identified in the bracket mural paintings of Gaeamsa Temple belong to the category of the types of pigments applied to the buddhist murals of the Joseon Dynasty investigated so far, and their production methods are similar. It has been reported that the conservation condition of the painting layer is relatively good compared to the wall, and, judging from the pigment used or the composition of the painting layer, no factors directly affecting the damage have been identified so far. The structure and materials of the bracket mural paintings of Daeungjeon Hall in Gaeamsa Temple, Buan have a similar manufacturing style in terms of the earthen wall layer, pigments, and techniques, compared to the Buddhist mural paintings in the Joseon Dynasty studied so far. Such information can provide useful data for diagnosing the conservation status of the bracket mural painting in Gaeamsa Temple and is expected to provide effective information on materials and technologies for conservation treatment planning.

\section{ACKNOWLEDGMENTS}

This paper was written as part of Konkuk University's research support program for its faculty on sabbatical leave in 2021 . 


\section{REFERENCES}

Chae, S.J., Yang, H.J. and Han, K.S., 2006, Nondestructive investigation of clay wall structure containing traditional mural paintings - The clay walls having mural paintings housed in the protective building in Muwisa temple, Kangjin, Jeollanamdo Province. Journal of Conservation Science, 18, 51-62. (in Korean with English abstract)

Fine Art Conservation Institute, 2006, Conservation report of murals of Geungnakjeon Hall at Muwisa Temple in Gangjin. Konkuk University, Chungju. (in Korean)

Han, K.S., 2003, Restoration and conservation of the buddhist mural paintings of Korea. Ph.D. Dissertation, University of Herzen State Pedagogical, Saint Petersburg. (in English)

Han, K.S., 2010, Estimation of damage degree for mural paintings in Maitreya Hall of Geumsan-sa buddhist temple, Korea. Journal of Conservation Science, 26(3), 293-310. (in Korean with English abstract)

Hwang, H.J., 2008, Earth architecture. CIR., Seoul. (in Korean)

Jeong, H.Y. and Han, K.S., 2008, Study on the making wall techniques behind the Budda in main building of Bongjeongsa Temple. Journal of Conservation Science, 23, 84-86. (in Korean with English abstract)

Lee, H.S., 2013, An analytical study of material characteristics for the conservation of Korean buddhist mural paintings. Ph.D. Dissertation, Dongguk University, Seoul. (in Korean with English abstract)

Lee, H.S., 2016, Study on material characterization of earthen wall of buddhist mural paintings in Joseon Dynasty. Journal of Conservation Science, 32(1), 84-86. (in Korean with English abstract)

Lee, H.S., Kim, S.H. and Han, K.S., 2018a, Scientific investigation for conservation methodology of bracket mural paintings of Daeungjeon Hall in Jikjisa Temple. Journal of Conservation Science, 34(2), 107-118. (in Korean with English abstract)

Lee, H.S., Lee, N.R. and Han, G.S., 2018b, Study on manufacturing techniques of bracket mural paintings of Daeungbojeon Hall in Naesosa Temple. Journal of Conservation Science, 34(6), 557-568. (in Korean with English abstract) 